\title{
PENGARUH BBLR TERHADAP KEJADIAN STUNTING PADA ANAK USIA 12-60 BULAN DI WILAYAH KERJA PUSKESMAS TANJUNG LANGKAT TAHUN 2017
}

\author{
The Effect of LBW on Stunting in Children Age 12-60 Months in Puskesmas \\ Working Area Tanjung Langkat 2017
}

\author{
Ade Ira Zahriany ${ }^{1}$ \\ ${ }^{1}$ Dosen Prodi D-III Kebidanan, Akademi Kebidanan Kharisma Husada \\ E-mail: nasutionadeira@gmail.com
}

\begin{abstract}
Abstrak
Gizi kurang menyebabakan prevalensi stunting (anak pendek) sangat tinggi, mempengaruhi satu dari tiga anak 12-60 bulan, yang merupakan proporsi yang menjadi masalah kesehatan masyarakat menurut kriteria Organisasi Kesehatan Dunia (WHO). Laporan Puskesmas Tanjung Langkat tentang penyakit infeksi yang diderita oleh balita di wilayah kerja Puskesmas Tanjung Langkat, penyakit ISPA dan Diare cukup tinggi diderita oleh balita yaitu $17,7 \%$ dan $29,8 \%$. Penelitian ini merupakan studi penelitian analitik dengan desain kasus kontrol yaitu penelitian analitik yang menyangkut bagaimana faktor risiko dipelajari dengan menggunakan pendekatan retrospective. Dengan kata lain, efek (penyakit atau status kesehatan) diidentifikasi pada saat ini, kemudian faktor risiko diidentifikasi ada atau terjadi pada waktu yang lalu. Hasil penelitian menunjukkan bahwa anak usia 12-60 bulan yang memiliki berat badan lahir rendah dan mendapatkan stunting di wilayah kerja Puskesmas Tanjung Langkat 58 padang tahun 2015 sebanyak 15 orang $(48,39 \%)$, sedangkan anak normal yang menderita stunting sebanyak 16 orang $(51,61 \%)$. Penelitian ini tidak sejalan dengan penelitian lainnya yang mengatakan bahwa anak stunting lebih banyak memilki riwayat berat badan lahir rendah. Diharapkan pada tenaga kesehatan Puskesmas Tanjung Langkat ketika mendapatkan anak yang lahir dengan keadaan berat badan lahir rendah, maka tenaga kesehatan memberikan informasi bahwa mereka memiliki risiko untuk menderita stunting (pendek), dan disarankan agar tetap menjaga kesehatan dan memperhatikan pola asuhnya.
\end{abstract}

Kata kunci: BBLR, Stunting Pada Anak Usia 12-60 Bulan

\begin{abstract}
Poor nutrition causes the prevalence of stunting (short children) to be very high, affecting one in three children 12 - 60 months, which is a proportion of public health problems according to the criteria of the World Health Organization (WHO). The Tanjung Langkat Health Center report on infectious diseases suffered by children under five in the Tanjung Langkat Health Center working area, ARI and Diarrhea is quite high among toddlers, namely $17.7 \%$ and $29.8 \%$. This research is an analytic research study with case control design, which is an analytic study concerning how risk factors are studied using a retrospective approach. In other words, the effects (illness or health status) are identified at this time, then identified risk factors exist or occurred in the past. The results showed that children aged 12-60 months who had low birth weight and got stunting in the working area of Tanjung Langkat 58 Padang Puskesmas in 2015 were 15 people (48.39\%), while normal children who suffered stunting were 16 people (51, $61 \%)$. This research is not in line with other studies which say that stunting children have more history of low birth weight. It is expected that Puskesmas Tanjung Langkat health workers will get children born with low birth weight, so health workers provide information that they have a risk of suffering from stunting (short), and are advised to maintain their health and pay attention to their parenting.
\end{abstract}

Keywords: LBW, Stunting in Children Aged 12-60 Months

\section{PENDAHULUAN}

Stunting adalah masalah gizi kronis yang disebabkan oleh asupan gizi yang kurang dalam waktu cukup lama akibat pemberian makanan yang tidak sesuai dengan kebutuhan gizi. WHO mengartikan stunting adalah keadaan tubuh yang 3 Riset Kesehatan Dasar (Riskesdas) tahun 2013 di Indonesia mencatat bahwa prevalensi stunting sebesar $37,2 \%$, meningkat dari tahun $2010(35,6 \%)$ dan tahun 2007 $(36,8 \%)$. Persentase tersebut dengan 
pembagian untuk kategori sangat pendek $19,2 \%$ dan pendek 18,1\%. Artinya, diperkirakan lebih dari sepertiga atau lebih dari 8,9 juta anak usia dibawah 5 tahun di Indonesia mengalami pertumbuhan yang tidak sesuai ukuran standar internasional untuk tinggi badan berbanding usia. Selain itu, untuk anak Indonesia yang dalam keadaan kurus, diperkirakan ada sekitar 3,3 juta anak.

Hasil Riskesdas tahun 2013 di provinsi Sumatera Barat mencatat prevalensi stunting sebesar $39,2 \%$. Prevalensi stunting tersebut meningkat dari tahun 2010 yang angkanya 32,7\%, dan tahun 2007 sebesar $36,5 \%$. Laporan tahunan Dinas Kesehatan Kabupaten Langkat dari tahun 2011 hingga tahun 2013 terjadi peningkatan prevalensi stunting. Pada tahun 2013 tercatat prevalensi stunting sebesar 28,3\%. Ini terjadi peningkatan dari tahun 2012 sebesar $27,93 \%$ dan peningkatan signifikan dari tahun tahun 2011 sebesar 17,83\%.

Kabupaten Langkat pada tahun 2014 merupakan kecamatan yang memiliki kasus tertinggi untuk kategori sangat pendek dari pada kecamatan lain yang ada di Kabupaten Langkat yaitu sebanyak 25 orang atau 8,39\%. Kabupaten Langkat terdiri dari satu Puskesmas yaitu Puskesmas Tanjung Langkat. Pada tahun 2015, terjadi peningkatan kasus stunting pada balita di Puskesmas Tanjung Langkat yang sebelumnya 25 kasus $(8,39 \%)$ menjadi 42 kasus (14\%). Pembagian kasus per umur adalah enam kasus pada usia 0-24 bulan dan 37 kasus pada 24-60 bulan. Data di Puskesmas Tanjung Langkat pada tahun 2015 mencatat bahwa angka kejadian kasus BBLR sebanyak 21 kasus $(7,05 \%)$. Pada tahun 2014 sebanyak 30 kasus, tahun 2013 sebanyak 11 kasus, dan pada tahun 2012 sebanyak 5 kasus.(11) 4 Gizi kurang yang terjadi pada anak-anak remaja dan saat kehamilan mempunyai dampak buruk terhadap berat badan lahir bayi. Berat badan lahir rendah $($ BBLR) $($ atau $=2.500$ gram $)$ pada masa neonatal maupun pada masa bayi selanjutya.(12, 13) Prediktor terkuat terjadinya stunting pada usia 12 bulan adalah berat badan lahir rendah. Sebagian besar bayi dengan BBLR mengalami gangguan pertumbuhan pada masa kanak- kanak. Di negara-negara Asia, seperti Bangladesh, RRC, India, Pakistan, Filipina, dan Sri Lanka, kejadian BBLR dapat memprediksi keadaan gizi anak pada masa prasekolah. Sebuah kesimpulan dari 12 studi yang telah dilakukan mengungkapkan bahwa pertumbuhan bayi yang IUGR (Intra Uterine Growth Retardation) akan mengalami kegagalan pertumbuhan pada dua tahun pertama.

Penelitian-penelitian diatas menjelaskan bahwa stunting lebih sering terjadi pada keluarga dengan pendapatan rendah, sehingga tingkat ekonomi keluarganya juga rendah. Keadaan ekonomi masyarakat di Puskesmas Tanjung Langkat cukup bervariasi, sehingga pendapatan yang didapatkan oleh keluarga juga bervariasi, mulai dari petani lebih kurang 46\%, Swata $24 \%$, PNS 17\%, ABRI 5\% sisanya bekerja di sektor informal lainnya. Namun kelompok dengan pendapatan rendah (keluarga miskin) menduduki proporsi yang cukup besar yaitu $22,4 \%$ dari total penduduk wilayah kerja Puskesmas Tanjung Langkat.

Laporan Puskesmas Tanjung Langkat tentang penyakit infeksi yang diderita oleh balita di wilayah kerja Puskesmas Tanjung Langkat, penyakit ISPA dan Diare cukup tinggi diderita oleh balita yaitu $17,7 \%$ dan 29,8\%. Untuk program ASI Ekslusif di Puskesmas Tanjung Langkat, cakupannya adalah $69,5 \%$ dari $75 \%$ yang ditargetkan.

Berdasarkan uraian yang telah di paparkan, peneliti tertarik untuk lebih lanjut mengenai "Pengaruh Berat Bayi Lahir Rendah (BBLR) dengan Kejadian Stunting pada anak berusia $12-60$ bulan di Wilayah Kerja Puskesmas Tanjung Langkat Kabupaten Langkat Tahun 2017’.

\section{BAHAN DAN METODE}

Lokasi penelitian dilakukan di Desa Tanjung Langkat yang berada di Kecamatan Salapian Kabupaten Langkat. Alasan pemilihan lokasi penelitian adalah karena berdasarkan survei pendahuluan yang dilakukan bahwa dari 25 anak tersebut terdapat 18 anak dengan kebiasaan konsumsi energi sedang, 14 anak dengan kebiasaan konsumsi protein rendah, dan 13 
anak dengan kebiasaan konsumsi seng rendah berdasarkan AKG (2013).

Populasi penelitian adalah subjek yang memenuhi kriteria yang telah ditetapkan. Populasi dalam penelitian ini adalah seluruh anak berusia 12-60 bulan di Desa Tanjung Langkat Kecamatan Salapian Kabupaten Langkat.

Sampel penelitian adalah objek yang diteliti dan dianggap mewakili seluruh

HASIL

Kondisi Sosial, Ekonomi dan Budaya

Sosial Dari segi kepercayaan, Mayoritas kepercayaan penduduk adalah Islam, dengan komposisi $99 \%$ Islam, sisanya katolik, Protestan, Buddha dan lain lain.

Ekonomi Keadaan ekonomi yang dilihat dari pekerjaan dan pendapatan penduduk di wilayah kerja Puskesmas Tanjung Langkat adalah bervariasi, mulai dari petani dengan kemampuan terbatas, sampai ke kelompok yang mapan, seperti swasta, PNS, ABRI, sisanya bekerja di sektor informal lainnya. Namun, kelompok dengan pendapatan rendah dan tidak menentu secara signifikan rawan dengan kesehatan yaitu keluarga miskin ternyata menduduki proporsi yang cukup besar dari total penduduk wilayah kerja Puskesmas Tanjung Langkat. populasi penelitian, sehingga dalam pengambilan sampel dibutuhkan teknik tertentu agar hasil penelitian valid (Notoatmodjo, 2010). Adapun kriteria dalam menentukan sampel pada penelitian ini adalah dengan menggunakan kriteria eksklusi. Sampel dalam penelitian ini adalah 58 sampel, dengan menggunakan metode Stratified Random Sampling.

\section{Analisis Univariat}

Analisis univariat yaitu analisis yang bertujuan untuk menjelaskan atau mendeskripsikan karakteristik setiap variabel penelitian. Analisis ini menghasilkan distribusi frekuensi dan persentasi dari setiap variabel.

\section{Karakteristik Anak}

Hasil pengumpulan data pada anak usia 12 - 60 bulan di wilayah kerja Puskesmas Tanjung Langkat Kabupaten Langkat, responden memiliki beberapa karakteristik yang meliputi jenis kelamin, umur, berat badan lahir, riwayat infeksi penyakit, dan ASI ekslusif. Karakteristik anak usia 12 60 bulan dalam penelitian ini dapat dilihat pada table berikut:

Tabel 1 Distribusi Frekuensi Karakteristik Anak

\begin{tabular}{ccccc}
\hline \multirow{2}{*}{ Variabel } & \multicolumn{2}{c}{ Kasus } & \multicolumn{2}{c}{ Kontrol } \\
\cline { 2 - 5 } & F & \% & f & \% \\
\hline Jenis Kelamin & & & & \\
Laki-Laki & 14 & 45,16 & 14 & 45,16 \\
Perempuan & 17 & 54,84 & 17 & 54,84 \\
\hline Umur & & & & \\
12-24 Bulan & 11 & 35,48 & 11 & 35,48 \\
25-36 Bulan & 10 & 32,36 & 10 & 32,36 \\
37-48 Bulan & 10 & 32,36 & 10 & 32,36 \\
\hline Berat Badan Lahir & & & & \\
BBLR & 15 & 48,39 & 7 & 22,58 \\
Normal & 16 & 51,61 & 24 & 77,42 \\
\hline Riwayat Infeksi Penyakit & & & & \\
Ya & 23 & 74,19 & 3 & 9,68 \\
Tidak & 8 & 25,81 & 28 & 90.72 \\
\hline Asi Eksklusip & 14 & 45,16 & 9 & 29.03 \\
Tidak Asi Eksklusip & 17 & 54,84 & 22 & 70.97 \\
\hline Jumlah & $\mathbf{3 1}$ & $\mathbf{1 0 0}$ & $\mathbf{3 1}$ & $\mathbf{1 0 0}$ \\
\hline & & & &
\end{tabular}


Distribusi frekuensi karakteristik anak pada tabel 1 menunjukkan bahwa distribusi kasus stunting di wilayah kerja Puskesmas Tanjung Langkat lebih banyak dengan jenis 49 kelamin perempuan $54,84 \%$ dari pada laki - laki 45,16\%. Usia anak terbanyak menderita stunting dari penelitian ini yaitu umur 12-24 bulan sebanyak

\section{Karakteristik Keluarga}

Hasil dari penelitian di dapatkan bahwa distribusi karakteristik dari keluarga anak usia $12-60$ bulan yaitu sebagai berikut :
35,48\% (11 anak. Anak yang lahir dengan berat badan lahir rendah pada usia 12-60 bulan lebih banyak pada kelompok kasus sebanyak 15 orang $(48,39 \%)$ dari pada kelompok kontrol sebanyak 7 orang $(22,58 \%)$.

Tabel 2. Distribusi Karakteristik Keluarga Responden

\begin{tabular}{lcccc}
\hline \multirow{2}{*}{ Variabel } & \multicolumn{2}{c}{ Kasus } & \multicolumn{2}{c}{ Kontrol } \\
\cline { 2 - 5 } & F & \% & F & \% \\
\hline Pendapatan & & & & \\
Rendah $(<$ UMR) & 26 & 83,87 & 21 & 67,74 \\
Tinggi (>UMR) & 5 & 16,13 & 10 & 32,26 \\
\hline \multicolumn{1}{c}{ Jumlah } & $\mathbf{3 1}$ & $\mathbf{1 0 0}$ & $\mathbf{3 1}$ & $\mathbf{1 0 0}$ \\
\hline
\end{tabular}

Distribusi frekuensi karakteristik keluarga pada tabel 4.2 menunjukkan bahwa anak yang berada di keluarga dengan tingkat pendapatan

\section{Analisis Bivariat}

Analisis bivariat untuk melihat variabel independen utama dan faktor risiko lainnya (variabel kovariat) dengan kejadian stunting pada anak usia 12-60 bulan.

\section{Hubungan Berat Badan Lahir Rendah Dengan Kejadian Stunting}

Hasil analisis hubungan berat badan lahir rendah dengan kajadian stunting dapat dilihat pada tabel berikut ini. rendah lebih banyak pada kelompok kasus 26 orang $(83,87 \%)$ dari pada kelompok kontrol sebanyak 21 orang $(67,74 \%)$.

Tabel 3. Hubungan berat badan lahir rendah dengan kejadian stunting

\begin{tabular}{|c|c|c|c|c|c|c|}
\hline \multirow{3}{*}{ Stunting } & \multicolumn{4}{|c|}{ Kontrol } & \multirow{3}{*}{$\begin{array}{c}\text { OR } \\
(95 \% \mathrm{CI})\end{array}$} & \multirow{3}{*}{$\begin{array}{c}P \text { - } \\
\text { Value }\end{array}$} \\
\hline & \multicolumn{2}{|c|}{ BBLR } & \multicolumn{2}{|c|}{ Normal } & & \\
\hline & $\mathbf{F}$ & $\%$ & $\mathbf{F}$ & $\%$ & & \\
\hline BBLR & 3 & 42,86 & 12 & 50 & 3 & \\
\hline Normal & 4 & 57,14 & 12 & 50 & $(0,97-9,3)$ & 0,049 \\
\hline Total & 7 & 100 & 24 & 100 & & \\
\hline
\end{tabular}

Berdasarkan tabel 3 didapatkan bahwa anak pada kasus dan kontrol yang memiliki berat badan lahir rendah yang menderita stunting sebanyak 3 orang, sedangkan anak yang lahir normal pada kasus dan kontrol
Analisis bivariat ini akan memperhatikan variabel kovariat yang akan masuk kedalam pemodelan multivariat dengan p-value $<0,25$. yang tidak menderita stunting sebanyak 12 orang. Hasil pengujian secara statistik diperoleh p-value 0,049 dengan nilai OR 3 $(0,97-9,3)$. Hal ini dapat disimpulkan bahwa terdapat hubungan yang signifikan 
antara berat badan lahir rendah terhadap kejadian stunting pada anak usia 12-60 bulan (p-value $<0,05)$. Anak yang memiliki berat badan lahir rendah berisiko sebesar 3 kali untuk menjadi stunting dibandingkan pada anak yang normal.

\section{Hubungan Pendapatan Keluarga Terhadap Kejadian Stunting}

Hasil analisis hubungan pendapatan

keluarga dengan kejadian stunting dapat

dilihat pada tabel berikut ini:

Tabel 4. Hubungan pendapatan keluarga dengan kejadian stunting

\begin{tabular}{|c|c|c|c|c|c|c|}
\hline \multirow{3}{*}{ Stunting } & \multicolumn{4}{|c|}{ Kontrol } & \multirow{3}{*}{$\begin{array}{c}\text { OR } \\
(95 \% \mathrm{CI})\end{array}$} & \multirow{3}{*}{$\begin{array}{c}P- \\
\text { Value }\end{array}$} \\
\hline & \multicolumn{2}{|c|}{$\begin{array}{l}\text { Pendapatan } \\
\text { Rendah }\end{array}$} & \multicolumn{2}{|c|}{$\begin{array}{c}\text { Pendapatan } \\
\text { Tinggi }\end{array}$} & & \\
\hline & $\mathbf{f}$ & $\%$ & f & $\%$ & & \\
\hline Pendapatan Rendah & 18 & 85,71 & 8 & 80 & 2,6 & \\
\hline Pendapatan Tinggi & 3 & 14,29 & 2 & 20 & $(0,7-10)$ & 0,145 \\
\hline Total & 21 & 100 & 10 & 100 & & \\
\hline
\end{tabular}

Berdasarkan tabel 4 didapatkan bahwa anak pada kasus dan kontrol yang berada di keluarga dengan tingkat pendapatan rendah yang menderita stunting sebanyak 18 orang, sedangkan anak yang berada di keluarga dengan tingkat pendapatan yang tinggi yang tidak menderita stunting sebanyak 2 orang.
Hasil pengujian secara statistik diperoleh pvalue 0,1459 dengan nilai OR 2,6 (0,7-10). Hal ini dapat disimpulkan bahwa tidak terdapat hubungan yang signifikan antara pendapatan keluarga terhadap kejadian stunting pada anak usia 12-60 bulan (pvalue $>0,05)$.

\section{Hubungan Riwayat Infeksi Penyakit Dengan Kejadian Stunting}

Hasil analisis hubungan riwayat infeksi penyakit terhadap kajadian stunting dapat dilihat pada table berikut ini.

Tabel 5. Hubungan riwayat infeksi penyakit dengan kejadian stunting

\begin{tabular}{|c|c|c|c|c|c|c|}
\hline \multirow{3}{*}{ Stunting } & \multicolumn{4}{|c|}{ Kontrol } & \multirow{3}{*}{$\begin{array}{c}\text { OR } \\
(95 \% \mathrm{CI})\end{array}$} & \multirow{3}{*}{$\begin{array}{c}P- \\
\text { Value }\end{array}$} \\
\hline & \multicolumn{2}{|c|}{$\begin{array}{c}\text { Pernah } \\
\text { Terinfeksi }\end{array}$} & \multicolumn{2}{|c|}{$\begin{array}{c}\text { Tidak Pernah } \\
\text { Terinfeksi }\end{array}$} & & \\
\hline & $\mathbf{F}$ & $\%$ & $\mathbf{F}$ & $\%$ & & \\
\hline Pernah Terinfeksi & 2 & 66,67 & 21 & 75 & 21 & \\
\hline Tidak Pernah Terinfeksi & 1 & 33,33 & 10 & 25 & $(2,8-156,2)$ & 0,001 \\
\hline Total & $\mathbf{0}$ & $\mathbf{0}$ & 31 & 100 & & \\
\hline
\end{tabular}

Berdasarkan tabel 5 didapatkan bahwa anak yang memiliki riwayat infeksi penyakit pada kasus dan kontrol yang menderita stunting sebanyak 2 orang, sedangkan anak yang tidak memiliki riwayat infeksi penyakit pada kasus dan kontrol yang tidak menderita stunting sebanyak 7 orang. Hasil pengujian secara statistik diperoleh p-value 0,001 dengan nilai OR $21(2,8-156,2)$. Hal ini dapat disimpulkan 52 bahwa terdapat hubungan yang signifikan antara riwayat infeksi penyakit kejadian stunting pada anak usia $12-60$ bulan ( $\mathrm{p}$ value $<0,05$ ). 


\section{Hubungan ASI Ekslusif Terhadap Kejadian Stunting}

Hasil analisis hubungan berat badan lahir rendah dengan kajadian stunting dapat dilihat pada table berikut ini.

Table 6. Hubungan ASI Ekslusif dengan kejadian stunting

\begin{tabular}{|c|c|c|c|c|c|c|}
\hline \multirow{3}{*}{ Stunting } & \multicolumn{4}{|c|}{ Kontrol } & \multirow{3}{*}{$\begin{array}{c}\text { OR } \\
(95 \% \mathrm{CI})\end{array}$} & \multirow{3}{*}{$\begin{array}{c}P- \\
\text { Value }\end{array}$} \\
\hline & \multicolumn{2}{|c|}{$\begin{array}{c}\text { ASI } \\
\text { Eksklusif }\end{array}$} & \multicolumn{2}{|c|}{$\begin{array}{l}\text { Tidak ASI } \\
\text { Eksklusif }\end{array}$} & & \\
\hline & f & $\%$ & $\mathbf{F}$ & $\%$ & & \\
\hline ASI Eksklusif & 4 & 44,44 & 10 & 45,45 & 2 & \\
\hline Tidak ASI Eksklusif & 5 & 55,56 & 12 & 54,55 & $(0,68-5,85)$ & 0,21 \\
\hline Total & 9 & 100 & 22 & 100 & & \\
\hline
\end{tabular}

Berdasarkan tabel 6 didapatkan bahwa anak pada kasus dan kontrol yang tidak ASI Ekslusif dan menderita stunting sebanyak 4 orang, sedangkan anak yang ASI Ekslusif pada kasus dan kontrol dan tidak menderita stunting sebanyak 12 orang. Hasil pengujian secara statistik diperoleh p-value 0,21 dengan nilai OR $2(0,68-5,85)$. Hal ini dapat disimpulkan bahwa tidak terdapat hubungan yang signifikan antara riwayat infeksi penyakit kejadian stunting pada anak usia 12-60 bulan ( $\mathrm{p}$ value $>0,05)$.

\section{Pemodelan Analisis Multivariat}

Analisis multivariat dilakukan untuk melihat hubungan variabel independen utama dan beberapa variabel kovariat secara bersamaan dengan variabel dependen, sehingga dapat diperkirakan hubungan variabel utama dan variabel dependen setelah dikontrol oleh variabel kovariat lainnya.

Tabel 7. Full Model Analisis Multivariat BBLR Terhadap Kejadian Stunting

\begin{tabular}{|c|c|c|c|c|}
\hline \multirow{2}{*}{ Stunting } & \multirow{2}{*}{ OR } & \multicolumn{2}{|c|}{$95 \% \mathrm{CI}$} & \multirow{2}{*}{$P$-Value } \\
\hline & & Lower & Upper & \\
\hline BBLR & 16,87 & 1,21 & 234,9 & 0,035 \\
\hline Pendapatan & 4,96 & 0,2 & 117,6 & 0,32 \\
\hline Riwayat Infeksi & 40,4 & 2,6 & 608,8 & 0,0075 \\
\hline ASI Eksklusif & 3 & 0,22 & 62,36 & 0,36 \\
\hline
\end{tabular}

Hasil uji statistik pada tabel di atas merupakan model awal untuk analisis multivariat selanjutnya, untuk mengetahui efek modifier dan efek confounding dari masing variabel secara bertahap. Berikut tahap-tahap analisis model yang dilakukan:

Tabel 8. Analisis Model Efek Modifikasi BBLR Dengan Kejadian Stunting

\begin{tabular}{lllll}
\hline \multirow{2}{*}{ Stunting } & \multirow{2}{*}{ OR } & $\mathbf{9 5 \%}$ CI & & \multirow{2}{*}{-Value } \\
\cline { 3 - 4 } & & Lower & Upper & \\
\hline BBLR & 16,87 & 1,21 & 234,9 & 0,035 \\
Pendapatan & 4,96 & 02 & 117,6 & 0,32 \\
Riwayat Infeksi & 40,4 & 2,6 & 608,8 & 0,0075 \\
ASI Eksklusif & 3 & 0,22 & 62,09 & 0,36 \\
BBLR*Pendapatan & 2,68 & 1,025 & 6,89 & 0,042 \\
BBLR*Riwayat Infeksi & 299666 & 0,001 & $>10 \mathrm{el}$ & 0,99 \\
BBLR*ASI Eksklusif & 1,4 & 0,011 & 226,94 & 0,85 \\
\hline
\end{tabular}

Hasil uji statistik pada tabel 8 merupakan model analisis interaksi/modifikasi. Dari hasil tersebut didapatkan bahwa pendapatan merupakan efek modifikasi terhadap hubungan berat 
badan lahir rendah dengan kejadian stunting pada anak usia 12-60 bulan ( $\mathrm{p}$-value $\geq 0,05$ ).

Selanjutnya akan dilakukan uji confounding BBLR terhadap kejadian stunting dengan variabel kovariat (pendapatan, riwayat infeksi, dan ASI Ekslusif). Langkahlangkah dalam melihat confounder yaitu dengan mengeluarkan variabel yang memiliki $p$-value dari model dan dilihat nilai $\Delta \mathrm{OR} \%$. Suatu variabel dikatakan sebagai confounder jika nilai $\Delta \mathrm{OR} \%$ nya lebih dari $10 \%$.

Variabel yang pertama kali dikeluarkan yaitu ASI Ekslusif, karena memiliki nilai p-value yang besar. Berikut adalah hasil setelah variabel ASI Ekslusif dikeluarkan.

Tabel 9. Model analisis model efek confounding tanpa ASI Ekslusif

\begin{tabular}{llll}
\hline Variabel & Orcrude & ORMLE & \% $\Delta \mathbf{O R}$ \\
\hline BBLR & 11,14 & 16,87 & 33,96 \\
Pendapatan & 3,24 & 4,96 & 34,68 \\
Riwayat Infeksi & 44,4 & 40,4 & 9,9
\end{tabular}

Berdasarkan hasil analisis dari tabel 4.9 didapatkan bahwa ASI Ekslusif merupakan efek confounding, karena nilai $\% \Delta \mathrm{OR}>10 \%$, sehingga ASI Ekslusif masuk dalam model selanjutnya. Model selanjutnya adalah dengan mengeluarkan variabel pendapatan, karena memiliki p-value yang besar setelah ASI Eksluisif. Berikut adalah hasil setelah variabel pendapatan dikeluarkan.

Tabel 10. Model analisis model efek confounding tanpa pendapatan

\begin{tabular}{llll}
\hline Variabel & Orcrude & ORMLE & \% $\Delta$ OR \\
\hline BBLR & 11,6 & 16,87 & 31,23 \\
Riwayat Infeksi & 44,28 & 40,4 & 9,6 \\
ASI Eksklusif & 2 & 3 & 33,3 \\
\hline
\end{tabular}

Berdasarkan hasil analisis dari tabel 10 didapatkan bahwa pendapatan merupakan efek confounding terhadap BBLR dengan kejadian stunting, karena nilai $\% \Delta \mathrm{OR}$ $>10 \%$, sehingga pendapatan masuk dalam model selanjutnya. Model selanjutnya adalah dengan mengeluarkan variabel riwayat infeksi. Berikut adalah hasil setelah variabel riwayat infeksi dikeluarkan.

Tabel 11. Model 3 analisis model efek confounding tanpa riwayat infeksi

\begin{tabular}{llll}
\hline Variabel & Orcrude & ORMLE & \% $\Delta$ OR \\
\hline BBLR & 6,15 & 16,87 & 63,5 \\
Pendapatan & 7,03 & 4,96 & 41,7 \\
ASI Eksklusif & 5,56 & 3 & 85,3 \\
\hline
\end{tabular}

Berdasarkan tabel 11 untuk melihat didapatkan $\% \Delta \mathrm{OR}>10 \%$. Dengan 56 confounding setelah variabel riwayat infeksi dikeluarkan dari model. Setelah demikian, riwayat infeksi penyakit merupakan confounding terhadap BBLR diuji, dengan kejadian stunting.

Tabel 12. Model akhir analisis multivariat Stunting

\begin{tabular}{lllll}
\hline \multirow{2}{*}{ Stunting } & \multirow{2}{*}{ OR } & \multicolumn{2}{c}{ 95\% CI } & \multirow{2}{*}{$\boldsymbol{P}$-Value } \\
\cline { 3 - 4 } & & Lower & Upper & \\
\hline BBLR & 16,87 & 1,21 & 234,9 & 0,035 \\
Pendapatan & 4,96 & 02 & 117,6 & 0,32 \\
Riwayat Infeksi & 40,4 & 2,6 & 608,8 & 0,0075 \\
\hline
\end{tabular}




\begin{tabular}{lllll}
\hline ASI Eksklusif & 3 & 0,22 & 62,09 & 0,36 \\
BBLR*Pendapatan & 2,68 & 1,025 & 6,89 & 0,042 \\
\hline
\end{tabular}

Berdasarkan tabel 12 tentang model akhir analisis multivariat didapatkan bahwa variabel pendapatan memiliki efek interaksi terhadap BBLR dengan kejadian stunting. Selanjutnya dalam uji confounding didapatkan bahwa

semua variabel merupakan confounder terhadap BBLR dengan kejadian stunting. Artinya, berat badan lahir rendah pada kondisi yang sama dengan pendapatan rendah dipengaruhi oleh variabel laninnya (riwayat infeksi dan ASi Ekslusif) untuk meningkatkan kejadian stunting sebesar 16,87 kali.

\section{PEMBAHASAN}

\section{Keterbatasan Penelitian}

Penelitian ini menggunakan metode case control. Kelemahan dari metode ini adalah berupa bias informasi dimana validasi mengenai informasi kadang-kadang sukar diperoleh. Secara teoritis banyak faktor lainnya yang berhubungan dengan kejadian stunting pada anak usia 12-60 bulan, dikarenakan keterbatasan yang dimiliki peneliti maka penelitian ini hanya meneliti beberapa variabel yang berhubungan langsung dengan stunting, antara lain pendapatan keluarga, riwayat infeksi penyakit, dan ASI Ekslusif.

\section{Karakteristik Keluarga}

Anak usia 12-60 bulan yang mengalami stunting dan memiliki keluarga yang berpendapatan rendah di wilayah kerja Puskesmas Tanjung Langkat padang tahun 2015 sebanyak 26 orang $(83,87 \%)$, dan yang tidak mengalami stunting sebanyak 21 orang $(67,74 \%)$. Penelitian ini menunjukkan bahwa anak usia 12-60 bulan yang menderita stunting lebih banyak berada di keluarga yang tingkat pendapatannya rendah yakni sebanyak $83,87 \%$. Hal ini sejalan dengan penelitian Sulistyoningsih bahwa meningkatnya pendapatan akan meningkatkan peluang untuk membeli pangan dengan kualitas dan kuantitas yang lebih baik. Sebaliknya, penurunan pendapatan akan menyebabkan menurunnya daya beli pangan yang baik secara kualitas maupun kuantitas.

\section{Analisis Bivariat \\ Hubungan BBLR Terhadap Kejadian Stunting}

Berdasarkan hasil penelitian dari BBLR terhadap kejadian stunting didapatkan $\mathrm{p}$ value 0,049 dan OR sebesar 3. Hal ini menunjukkan bahwa terdapat hubungan antara BBLR dengan kejadian stunting pada anak usia 12-60 bulan di wilayah kerja Puskesmas Tanjung Langkat pada tahun 2015. Anak usia 12-60 bulan yang memiliki riwayat berat badan lahir rendah memiliki risiko 3 kali mengalami stunting. Hasil ini sesuai dengan penelitian yang dilakukan oleh Ristanti di wonosobo yang mendapatkan bahwa BBLR memiliki hubungan yang signifikan terhadap kejadian stunting. Penelitian lainnya yang mendapatkan hasil yang sama dengan ini yaitu penelitian yang dilakukan oleh Sirajudin tahun 2011 menyatakan bahwa anak pendek 3 kali lebih besar di banding non BBLR, pertumbuhan terganggu, penyebab wasting, dan risiko malnutrisi.

Berat badan lahir rendah adalah gambaran multimasalah kesehatan masyarakat mencakup ibu yang kekurangan gizi jangka panjang, kesehatan yang buruk, kerja keras dan perawatan kesehatan dan kehamilan yang buruk. Secara individual, BBLR merupakan predictor penting dalam kesehatan dan kelangsungan hidup bayi yang baru lahir dan berhubungan dengan risiko tinggi pada anak.

Berat lahir pada umumnya sangat terkait dengan pertumbuhan dan perkembangan jangka panjang. Sehingga, dampak lanjutan dari BBLR dapat berupa gagal tumbuh (grouth faltering). Seseorang bayi yang lahir dengan BBLR akan sulit dalam mengejar ketertinggalan pertumbuhan awal. Pertumbuhan yang tertinggal dari yang normal akan menyebabkan anak tersebut menjadi stunting.

\section{Hubungan Pendapatan Keluarga Terhadap Kejadian Stunting}

Berdasarkan hasil penelitian antara pendapatan keluarga terhadap kejadian stunting didapatkan p-value 0,145 dan OR sebesar 2,6. Hal ini menunjukkan bahwa 60 tidak terdapat hubungan yang siginfikan 
antara pendapatan keluarga dengan kejadian stunting pada anak usia 12-60 bulan di wilayah kerja Puskesmas Tanjung Langkat pada tahun 2015. Akan tetapi, pendapatan keluarga memiliki risiko terhadap kejadian stunting. Anak usia 12-60 bulan yang berada di keluarga dengan tingkat ekonomi rendah memiliki risiko 2,6 kali mengalami stunting.

Penelitian ini tidak sejalan dengan penelitian dari Ngaisyah yang mendapatkan bahwa pendapatan berhubungan secara signifikan terhadap kejadian stunting. Akan tetapi, pe nelitian ini sejalan dengan penelitian oleh Hidayah tahun 2013 yang mendapatkan bahwa pendapatan keluarga tidak berhubungan secara signifikan terhadap kejadian stunting, tetapi memiliki risiko untuk mendapatkan stunting.

Pendapatan adalah hasil yang diperoleh dari kerja atau usaha yang telah dilakukan. Pendapatan akan mempengaruhi gaya hidup seseorang, dan pemilihan asupan makanan. Orang atau keluarga yang mempunyai status ekonomi atau pendapatan tinggi akan mempraktikkan gaya hidup yang mewah misalnya lebih komsumtif karena mereka mampu untuk membeli semua yang dibutuhkan bila dibandingkan dengan keluarga yang kelas ekonominya kebawah. Peningkatan pendapatan rumah tangga berhubungan dengan penurunan dramatis terhadap probabilitas stunting pada anak. Beberapa studi menunjukkan bahwa peningkatan pendapatan pada penduduk miskin adalah strategi untuk membatasi tingginya kejadian stunting dalam sosial ekonomi rendah pada segmen populasi. Malnutrisi terutama stunting, lebih dipengaruhi oleh dimensi sosial ekonomi, sehingga harus dilihat dalam konteks yang lebih luas dan tidak hanya dalam ranah biomedis. Status ekonomi rumah tangga juga memilki efek yang signifikan terhadap kejadian malnutrisi kronis pada anak di Ethiopia.

Kabupaten Langkat memiliki status sosial ekonomi yang cukup bervariasi. Rata rata pekerjaan masyarakat di Pauh adalah buruh harian lepas. Keadaan kasus dan kontrol di Pauh sudah terbiasa dengan keadaan ekonomi mereka yang mencukupi kebutuhan hariannya. Sehingga pendapatan keluarga tidak memiliki hubungan yang signifikan terhadap kejadian stunting pada anak usia 12-60 bulan di wilayah kerja Puskesmas Tanjung Langkat.

\section{Hubungan Riwayat Penyakit Infeksi Terhadap Kejadian Stunting}

Hasil penelitian ini ditemukan adanya hubungan yang signifikan antara riwayat infeksi penyakit dengan kejadian stunting, dengan p-value 0,0001 , dan OR 21. Hal ini dapat disimpulkan bahwa anak usia 12-60 bulan yang mendapat penyakit infeksi berisiko 21 kali untuk menderita stunting. Penelitian ini sejalan dengan penelitian dari Oktarina tahun 2012 yang mendapatkan bahwa penyakit infeksi memiliki hubungan yang signifikan terhadap kejadian stunting. Balita yang memiliki riwayat infeksi penyakit ketika balita, maka akan lebih berisiko menderita stunting sebesar 4 kali dari pada balita yang tidak memiliki riwayat infeksi penyakit.

Infeksi adalah pertumbuhan organisme parasit didalam tubuh. Organisme parasit adalah salah satu yang hidup pada atau dalam organisme lain dan makanan yang menarik daripadanya. Seseorang yang terkena infeksi telah organisme lain (kuman) tumbuh dalam dirinya, gambar makanan dari orang itu. Infeksi adalah invasi (masuk ke dalam tubuh) dan multiplikasi (pertumbuhan dan perkembangan) mikroorganisme patogen dibagian tubuh atau jaringan, yang dapat menghasilkan cedera jaringan berikutnya dan kemajuan untuk terbuka penyakit melalui berbagai mekanisme seluler atau beracun.

Riwayat penyakit infeksi berhubungan dengan kejadian stunting pada anak usia 1260 bulan. Penyakit infeksi mempunyai efek substansial terhadap 62 pertumbuhan anak. Penyakit infeksi yang diderita oleh anak, biasanya akan terjadi kenaikan suhu tubuh, sehingga juga akan terjadi kenaikan kebutuhan zat gizi. Kondisi tersebut apabila tidak diimbangi oleh asupan makan, asupan gizi yang adekuat, maka akan timbul malnutrisi dan gagal tumbuh. Masyarakat di wilayah kerja Puskesmas Tanjung Langkat 
sering mengetahui anaknya mendapatkan penyakit infeksi. Akan tetapi ini tidak cepat ditangani langsung atau tidak di bawa ke Puskesmas, karena mereka beranggapan bahwa itu adalah hal yang biasa terjadi pada anak balita. Seandainya sudah terjadi hal kronis, lalu mereka membawa dan melaporkan kepada pihak kesehatan. Itulah yang menjadi kondisi dan kebiasaan masyarakat sehingga secara tidak langsung anak balita di Pauh menderita penyakit infeksi dan berdampak secara signifikan terhadap kejadian stunting pada anak usia 12-60 bulan.

\section{Hubungan Pemberian ASI Ekslusif Terhadap Kejadian Stunting}

Hasil penelitian ini tentang ASI Ekslusif terhadap kejadian stunting didapatkan pvalue $>0,05$, dan $\mathrm{OR}=2(0,68-5,85)$. Hal ini menunjukkan bahwa pemberian ASI Ekslusif tidak berhubungan secara signifikan terhadap kejadian stunting. Akan tetapi, jika tidak memberikan ASI Ekslusif akan meningkatkan risiko sebesar 2 kali terhadap kejadian stunting.

Hasil ini tidak sejalan dengan penelitian oleh Hidayah tahun 2013 yang menemukanan bahwa ada hubungan bermakna antara ASI eksklusif dengan kejadian stunting pada anak balita. Akan tetapi, hasil penelitian ini sejalan dengan penelitian Anshori yang mendapatkan bahwa ASI Ekslusif bukan merupakan faktor risiko kejadian stunting pada anak balita. Pemberian ASI Ekslusif tidak memiliki hubungan dengan kejadian stunting pada anak usia 12-60 bulan.

Hal ini terjadi karena sebagian besar pada kelompok kedua kelompok tidak memberikan ASI Ekslusif. Sebagian besar ibu pada kedua 63 kelompok banyak yang memberikan ASI dengan kombinasi susu formula. ASI tidak memiliki hubungan pada penelitian ini dimungkinkan karena ASI Ekslusif berpengaruh pada usia tertentu, yakni 0-6 bulan. Keluarga yang memberikan pola asuh baik terutama terhadap kebutuhan zat gizi, maka akan memepengaruhi status gizi anak. Pemberian MP-ASI yang tepat pada anak usia 12-24 bulan akan menurunkan risiko malnutrisi, karena pada usia tersebut kebutuhan zat gizi anak tidak dapat tercukupi hanya dari ASI saja.

ASI Ekslusif yang tidak diberikan pada bayi memiliki risiko terhadap kejadian stunting. Dalam pemberian ASI Ekslusif pada anak di Puskesmas Tanjung Langkat baik pada kasus dan kontrol, masyarakat lebih banyak tidak menggunakan ASI Ekslusif. Hal ini dikarenakan ketika anak mereka memasuki usia 3 atau 4 bulan, sulit untuk minum ASI. Sehingga ibu merasa kasihan dan memberikan makanan tambahan, seperti susu formula, sehingga anak tersebut sudah tidak termasuk lagi ASI Ekslusif.

\section{Pemodelan Analisis Mulivariat}

Berdasarkan hasil penjaringan analisis multivariat dari variabel independen utama (BBLR) dan variabel kovariat (pendapatan, riwayat infeksi penyakit, dan ASI Ekslusif) menyatakan bahwa BBLR dan riwayat infeksi penyakit terdapat hubungan yang signifikan terhadap kejadian stunting pada anak usia 12-60 bulan.

Analisis multivariat melihat dua hal yaitu efek interaksi dan efek confounding. Hasil penelitian dalam melihat efek interaksi didapatkan bahwa variabel pendapatan merupakan efek interaksi BBLR terhadap kejadian stunting. Hasil penilitian dalam melihat efek confounding didapatkan bahwa semua variabel kovariat (pendapatan, riwayat infeksi, dan ASI Ekslusif) merupakan confounder terhadap BBLR dengan kejadian stunting pada anak usia 12-60 bulan. Hal tersebut dapat diartikan bahwa anak yang BBLR pada kondisi yang sama dipengaruhi oleh variable lainnya (pendapatan, Riwayat infeksi, dan ASI Ekslusif) meningkatkan 64 risiko untuk menderita stunting yang sebelumnnya sebesar 3 kali menjadi 16,87 kali.

Bayi yang baru lahir memiliki beberapa kemungkinan yang akan terjadi, diantaranya lahir dengan berat badan lahir rendah (BBLR) dan normal. Bayi akan mengalami masalah cukup besar ketika lahir dengan BBLR. Ia akan mengalami risiko untuk menjadi stunting. Stunting 
yang disebabkan oleh growth faltering dan catch up growth yang tidak memadai, mencerminkan ketidakmampuan untuk mencapai pertumbuhan optimal. Akan tetapi, jika diberikan dukungan asupan gizi yang adekuat maka pola pertumbuhan normal dapat terkejar (catch up). Asupan gizi yang adekuat berkaitan dengan kualitas dan kuantitas makanan yang diberikan. Hal ini dipengaruhi oleh pendapatan keluarga. Pendapatan yang rendah berdampak pada ketidakmampuan untuk mendapatkan pangan yang cukup dan berkualitas karena rendahnya kemampuan daya beli.

Kondisi ini membuat balita stunting sulit mendapatkan asupan zat gizi yang adekuat sehingga mereka tidak dapat mengejar ketertinggalan pertumbuhan (catch up) dengan baik.(42, 44) Hasil penelitian menunjukkan bahwa pendapatan merupakan efek interaksi dan confounding terhadap BBLR dengan kejadian stunting, dan memiliki risiko sebesar 2,96 kali. Pendapatan yang rendah pada kelompok stunting selain berdampak asupan gizi yang adekuat, juga berdampak pada higyene dan sanitasi yang rendah. Anak yang tinggal di lingkungan dengan sanitasi rendah lebih rawan terkontaminasi bakteri. Penelitian di Bangladesh melaporkan bahwa komponen Proteobacteria seperti Klebsiella, Escherichia dan Neisseria yang merupakan bakteri patogen, berjumlah lebih banyak pada anak yang malnutrisi. Penelitian lain di India melaporkan bahwa spesies Campylobacter dan Helicobacter sebagai penyebab diare dan infeksi lainnya ditemukan berjumlah lebih banyak pada anak 65 malnutrisi, sehingga berakibat pada malabsorbsi zat gizi dan penurunan kesehatan. Growth faltering dapat terjadi ketika asupan makanan dan absorbsi zat gizi oleh vili berkurang tetapi kebutuhan zat gizi untuk pertumbuhan meningkat. $(45,46)$ Rekomendasi dari The American Dietetic Association (ADA) dan The American Academy of Pediatric (AAP) adalah memberikan ASI Ekslusif.

Hal tersebut dapat menyebabkan growth faltering karena bayi mengalami defisisensi zat gizi. Sebuah penelitian di Senegal menyatakan bahwa ASI eksklusif 66 yang diberikan selama lebih dari 2 tahun berhubungan dengan rata-rata $\mathrm{z}$-score $\mathrm{TB} / \mathrm{U}$ yang rendah. Pada penelitian tersebut, ditemukan prevalensi stunting yang lebih tinggi pada balita yang diberikan ASI eksklusif selama lebih dari 2 tahun.

Riwayat infeksi memiliki confounding terhadap BBLR dengan kejadian stunting. Penyakit infeksi mempunyai efek substansial terhadap pertumbuhan anak. Penyakit infeksi yang diderita oleh anak, biasanya akan terjadi kenaikan suhu tubuh, sehingga juga akan terjadi kenaikan kebutuhan zat gizi. Kondisi tersebut apabila tidak diimbangi oleh asupan makan, asupan gizi yang adekuat, maka akan timbul malnutrisi dan gagal tumbuh. Anak yang BBLR membutuhkan asupan gizi untuk mengejar pertumbuhan yang tertinggal dari anak yang normal. Anak yang BBLR dan mendapatkan penyakit infeksi akan semakin meningkatkan risiko menderita stunting karena asupan gizi yang harus didapatkan oleh mereka.

\section{KESIMPULAN}

Berdasarkan hasil penelitian dan pembahasan yang telah di uraikan sebelumnya, maka dapat disimpulkan sebagai berikut :

1. Anak yang menderita stunting di wilayah kerja Puskesmas Tanjung Langkat pada tahun 2015 hampir setengahnya $(35,48 \%)$ berada pada usia 12-24 bulan, sekitar $3 / 4 \quad(74,16 \%)$ menderita penyakit infeksi, dan yang tidak mendapatkan ASI Ekslusif $(45,16 \%)$, dan lebih $3 / 4(83,87 \%)$ berada dikeluarga dengan tingkat pendapatan yang rendah.

2. Terdapat hubungan yang signifikan antara BBLR dengan kejadian stunting pada anak usia 12-60 bulan. Anak yang lahir dengan berat badan lahir rendah memiliki risiko untuk menderita stunting sebesar 3 kali.

Tidak terdapat hubungan pendapatan keluarga pada BBLR dengan kejadian stunting pada anak usia 12-60 bulan di wilayah kerja Puskesmas Tanjung Langkat pada tahun 2015. 
3. Terdapat hubungan riwayat penyakit infeksi penyakit pada BBLR dengan kejadian stunting pada anak usia 12-60 bulan di wilayah kerja Puskesmas Tanjung Langkat pada tahun 2015.

4. Anak yang lahir dengan berat badan lahir rendah dipengaruhi oleh beberapa faktor untuk menderita stunting pada usia 12-60 bulan, yaitu pendapatan, ASI Ekslusif, dan Riwayat infeksi.

\section{SARAN}

\section{Bagi Puskesmas}

Diharapkan pada tenaga kesehatan Puskesmas Tanjung Langkat ketika mendapatkan anak yang lahir dengan keadaan berat badan lahir rendah, maka tenaga kesehatan memberikan informasi bahwa mereka memiliki risiko untuk menderita stunting (pendek), dan disarankan agar tetap menjaga kesehatan dan memperhatikan pola asuhnya.

Diharapkan agar melakukan penyuluhan dan memotivasi masyarakat untuk memberikan ASI Ekslusif. Bayi yang tidak mendapatkan ASI Ekslusif berisiko untuk menderita stunting.

Diharapkan kepada kader yang ada di Puskesmas Tanjung Langkat agar memberikan informasi kepada masyarakat dan orang tua agar memberikan ASI Ekslusif dan memperhatikan pola asuh yang baik, baik dalam pemantauan keadaan gizi dan penyakit yang dialami oleh anaknya.

\section{Bagi Peneliti Selanjutnya}

Diharapkan peneliti selanjutnya dapat memperluas penelitian dengan menambah variabel lain yang memiliki pengaruh. Selain itu, diharapkan juga untuk penelitian selanjutnya dapat melanjutkan dengan metode penelitian dan analisis yang lebih tingkat ke validitasnya (mengurangi bias) dalam penelitian, seperti metode kohort, dan lain-lain

\section{DAFTAR PUSTAKA}

Almatsier, S. 2001. Prinsip Dasar Ilmu Gizi. Jakarta: PT Gramedia Pustaka Utama;. Ngaisyah RD

Anshori H, A. 2013. Faktor Risiko Kejadian Stunting Pada Anak Usia
12-24 Bulan Universitas

Diponegoro.

Balitbangkes. 2010. Riset Kesehatan Dasar. Jakarta: Departemen Kesehatan RI.

Balitbangkes, 2013. Riset Kesehatan Dasar. Jakarta: Kementerian Kesehatan RI.

Buku Kedokteran. Balitbangkes. 2007. Riset Kesehatan Dasar. Jakarta: Kementerian Kesehatan RI.

Hidayah, F. 2013. ASI Eksklusif sebagai Faktor Risiko Kejadian Stunting Pada Anak Usia 6-24 Bulan di Kota Yogyakarta. Universitas Gajah Mada; Rosha BC, Putri DSK, Putri IYS. Determinan Status Gizi Pendek Anak Balita dengan Riwayat Berat Badan Lahir Rendah di Indonesia (BBLR) di INDONESIA (Analaisis Data Riskesdas 2007-2010). Jurnal Ekologi Kesehatan.

Hidayah, F. 2013. ASI Eksklusif sebagai Faktor Risiko Kejadian Stunting Pada Anak Usia 6-24 Bulan di Kota Yogyakarta. Universitas Gajah Mada.

Humphrey J, H. 2009. Child undernutrition, tropical enteropathy, toilets and handwashing. Lancet.

Maryanto, S. 2015. Anugrah RM. Hubungan antara penyakit tuberkulosis paru ( $\mathrm{Tb}$ paru) dan BBLR dengan kejadian stunting pada siswa kelas 1 di SD negeri Sambek kecamatan Wonososbo.

Morrice JS, Suliva PB. 2005.Failure to thrive/ malnutrition. In: Guandalini $\mathrm{S}$, editor. Essential pediatric gastroenterology. USA: The MacGraw-Hill Companies.

Nasution, D., Nurdiati, D., dan Huriyati, E. 2014. Berat Badan Lahir Rendah dengan Kejadian Stunting Pada Anak Usia 6-24 bulan. Jurnal Gizi Klinis Indonesia Nasional.

Oktarina Z. 2010. Hubungan Berat Lahir dan Faktor-Faktor Lainnya dengan Kejadian Stunting pada Balita Usia 24-59 Bulan di Provinsi Aceh, Sumatera Utara, Sumatera Selatan, dan Lampung pada Tahun 2010. Jakarta: Universitas Indonesia; 
Profil Kesehatan Kabupaten Langkat. Padang: Dinas Kesehatan KotaLangkat; 2012. DKK. Profil Kesehatan Kabupaten Langkat. Dinas Kesehatan Langkat; 2011.

Profil Kesehatan Kabupaten Langkat: Dinas Kesehatan Langkat; 2013. DKK.

Rahayu, A. Yulidasari, F., Putri, A., Rahman, F. 2015. Riwayat Berat Badan Lahir Proyek Kesehatan dan Gizi berbasis Masyarakat Untuk Mengurangi Stunting. In:
Rudert C. Malnutrition In Asia. Vientiane: UNICEF East Asia Pacific; 2014. Dewa Nyoman Supariasa BB, Ibnu Fajar. Penilaian Status Gizi. Jakarta: Penerbit

UNICEF. 2012. Ringkasan Kajian Gizi. Jakarta: Pusat Promosi KesehatanKementerian Kesehatan RI. 